\title{
Social Media in Organizations Leveraging Personal and Collective Knowledge Processes
}

\author{
Razmerita, Liana; Kirchner, Kathrin; Nabeth, Thierry
}

Published in:

Journal of Organizational Computing and Electronic Commerce

DOI:

10.1080/10919392.2014.866504

Publication date:

2014

Citation for published version (APA):

Razmerita, L., Kirchner, K., \& Nabeth, T. (2014). Social Media in Organizations: Leveraging Personal and

Collective Knowledge Processes. Journal of Organizational Computing and Electronic Commerce, 24(1), 74-93. https://doi.org/10.1080/10919392.2014.866504

Link to publication in CBS Research Portal

\section{General rights}

Copyright and moral rights for the publications made accessible in the public portal are retained by the authors and/or other copyright owners and it is a condition of accessing publications that users recognise and abide by the legal requirements associated with these rights.

Take down policy

If you believe that this document breaches copyright please contact us (research.lib@cbs.dk) providing details, and we will remove access to the work immediately and investigate your claim. 


\title{
Social Media in Organizations: Leveraging Personal and Collective Knowledge Processes
}

\author{
Liana Razmerita, Kathrin Kirchner, and Thierry Nabeth
}

Post print (Accepted manuscript)

This is an Accepted Manuscript of an article published by Taylor \& Francis Group in Journal of Organizational Computing and Electronic Commerce 22 Nov 2013, available online:

http://www.tandfonline.com/10.1080/10919392.2014.866504

Uploaded to Research@CBS: September 2015.

Available at:

http://research.cbs.dk/da/publications/social-media-in-organizations\%2873bafc84-e8f0-4fca-a973-

918119aea388\%29.html

(C) 2013 Taylor \& Francis 


\section{ACCEPTED MANUSCRIPT}

\section{Social Media in ORganizations: \\ Leveraging Personal And Collective \\ KnOWLedge Processes}

\section{SHORT TITLE}

\section{Leveraging Personal And Collective Knowledge Processes}

Authors: Liana Razmerita ${ }^{\mathrm{a}}$, Kathrin Kirchner $^{\mathrm{b}}$, Thierry Nabeth ${ }^{\mathrm{c}}$

${ }^{a}$ Department of International Business Communication, Copenhagen Business School, Dalgas Have 15, Frederiksberg 2000, Denmark, 1r.ibc@cbs.dk

${ }^{\mathrm{b}}$ University Hospital Jena, Bachstrasse 18, 07743 Jena, Germany, kathrin.kirchner@uni-jena.de

${ }^{c}$ RITM, Faculté Jean Monnet, University Paris Sud, 54, Boulevard Desgranges 92330 Sceaux, France, thierry.nabeth@u-psud.fr

Corresponding Author:

Liana Razmerita

Copenhagen Business School

Dalgas Have 15, Office $2 \varnothing 102$

Frederiksberg 2000, Denmark

Email: 1r.ibc@cbs.dk

Web http://www.cbs.dk/staff/liana/

\section{BIOS}

Liana Razmerita is Associate Professor at Copenhagen Business School in Denmark. She has published over 50 articles in journals, books, and conference proceedings. The journals include IEEE Systems, Man and Cybernetics, Journal of Applied Artificial Intelligence, Online Information Review, Business Information Review, and Interacting with Computers. Her current research focuses on the use of novel information and communication technologies in an organizational context and in learning environments. In particular, an important strand of her current research investigates how social media impacts the way people manage knowledge work including: collaboration, innovation and learning. Furthermore, Professor Razmerita has

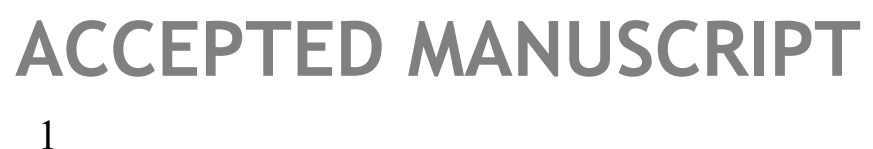




\title{
ACCEPTED MANUSCRIPT
}

published in the areas of user modeling, interactive system design, e-government, and knowledge management.

Kathrin Kirchner is a post-doctoral researcher at University Hospital Jena, Germany, where she works in the project "Process Intelligence in Healthcare". She holds a PhD in information systems from Friedrich Schiller University Jena (FSU). Dr. Kirchner was previously employed as a researcher and lecturer at FSU in the department of information systems. Her main research fields are knowledge management, cooperative process modelling, and data mining. She is interested in the usage of social media in companies fostering knowledge management and collaboration. Another research stream deals with the cooperation of different stakeholders in the process of process elicitation and modeling, especially in healthcare processes driven by expert knowledge.

Thierry Nabeth is a doctoral candidate in the Lab RITM (Réseau, Innovation, Territoire \& Mondialisation) at the University of Paris Sud. The focus of his research is investigating the functioning and role of nonverbal communication in social media, using a neuroscience approach. He was previously, and for many years, a senior research fellow at the INSEAD CALT (Centre for Advanced Learning Technologies http://www.calt.insead.edu/), and has been involved in many research projects on subjects such as online communities, knowledge management, and technology-enhanced learning, with a specific focus on online participation, online identity, and attention management.

\begin{abstract}
By using social media, many companies try to exploit new forms of interaction, collaboration, and knowledge sharing through leveraging the social, collaborative dimension of social software. The traditional collective knowledge management model based on a top-down approach is now opening up new avenues for a bottom-up approach incorporating a more personal knowledge management dimension, which could be synergized into collective knowledge using the socialcollaborative dimension of social media. This article addresses the following questions: (1) How can social media support the management of personal and collective knowledge using a synergetic approach? (2) Do the personal and collective dimensions compete with each other or can they reinforce each other in a more effective manner using social media?
\end{abstract}

\section{ACCEPTED MANUSCRIPT}




\section{ACCEPTED MANUSCRIPT}

Our findings indicate that social media supports both the personal and collective dimensions of knowledge, while integrating a social collaborative dimension. The paper introduces a framework that classifies social software into four categories according to the level of interaction and control. With certain tools, individuals are more in control. With other tools, the group is in control, resulting in a higher level of interaction and a diversity of knowledge and mindsets brought together. However, deploying and adopting these new tools in an organizational context is still a challenging task for management, owing to both organizational and individual factors.

Keywords: social media, personal knowledge management, knowledge management, social networks, Enterprise 2.0, social software.

\section{Introduction}

The massive adoption of social media has turned the web into a social space and has provided unique ways of supporting social processes along with the management of data, information and knowledge. With the emergence of social media, new terms such as Enterprise Social Software (ESS), social software-based knowledge management (Von Krogh 2012), Enterprise 2.0 (McAfee 2009, 2006), or social business are appearing. All acknowledge the central role of collaboration and support of social processes for communication and managing knowledge in the modern enterprise. Using social media, companies are exploring new ways to cultivate and exploit knowledge sharing with their customers, suppliers, and partners both inside the organization and outside strict organizational boundaries. 


\section{ACCEPTED MANUSCRIPT}

Social media, often used interchangeably with social software, has been adopted in organizations to support both the personal and collective process of managing knowledge. Social software includes a wide range of communication tools, often based on Internet technologies (e.g., instant messaging, text chats, forums, virtual worlds, as well as social media). Social software emerged from groupware and computer-supported collaborative work and it supports group interaction (Haefliger et al. 2011). Social media is built on the ideological and technological foundations of Web 2.0, a platform for social interaction, communication, and collaboration that allows creation and exchange of user-generated content (Kaplan and Haenlein 2010; O'Reilly 2005). At the same time, even in the social media era, the management of knowledge remains something profoundly personal. First, this is because ultimately knowledge is created, processed, applied, and exchanged by individuals. Second, contribution to knowledge repositories, and participation in the collective process, is often individually motivated.

While the management of knowledge in an organizational context is generally associated with the management of collective knowledge, little research addresses the Personal Knowledge Management (PKM) issues, and even fewer articles discuss the articulation of personalcollective knowledge. This article examines these two dimensions of knowledge and their possible synergetic or conflicting articulation using social media. It also discusses the impact of social media on the management of knowledge processes and, in particular, the integration of personal into collective knowledge for knowledge creation, and harnessing collective intelligence through social collaborative processes. The article draws on the organizational knowledge creation theory (Nonaka and Von Krogh 2009; Nonaka, Toyama, and Konno 2000; Nonaka, Von Krogh, and Voelpel 2006), provides a broad literature review, and undertakes a 


\section{ACCEPTED MANUSCRIPT}

systematic analysis of both personal and collective knowledge. The following two questions are addressed: (1) How can social media support the management of knowledge from a personal and collective perspective? (2) Do the personal and collective dimensions compete with each other or can they reinforce each other in a more effective manner using social media?

Furthermore this paper analyzes and discusses the main social web technologies that are used to support knowledge processes in the enterprise, taking into account both the personal and collective perspectives of knowledge articulation, and looking at both benefits and challenges.

The article is structured as follows. The next section introduces the research methodology. Section 3 provides a literature review of both the personal and collective perspectives of knowledge management, as well as how the two are articulated. Section 4 overviews a core set of social media applications used in an organizational context. Section 5 discusses how the personal and collective dimensions can be articulated using social media. It analyzes benefits and limitations of managing knowledge using social media, and it introduces a framework for classification of social media taking into account the level of interaction and control. Section 6 summarizes our findings.

\section{Research MethodoLogy}

In order to examine how personal and collective dimensions of knowledge are articulated, we adopt a two-phase approach: a literature review followed by a comparison of the characteristics of a core set of social software used in an organizational context. In Phase I, we review articles in the areas of "Personal Knowledge Management" (PKM), "Collective Knowledge Management"

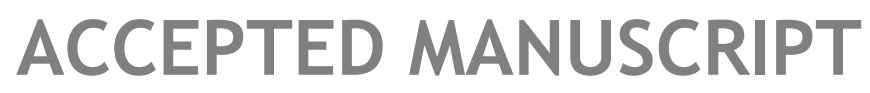




\section{ACCEPTED MANUSCRIPT}

(CKM), the articulation between PKM and CKM using social media, including consultancy reports, previous surveys, and case studies. We argue that the terms "collective knowledge" and "collective knowledge management" appear to have been implicitly associated with the classical knowledge management concept. The literature review is subsequently used to synthesize the key conceptual streams presented in the sections below. We divide the papers into three categories: those covering only the personal dimension of knowledge management, those covering only the collective dimension, and finally the papers covering both the personal and the collective dimensions. In the last category, we consider, in particular, the articles that address explicitly the articulation between the personal and the collective dimensions.

Phase II examines social media in relation to the degree to which they support both the personal and collective dimensions based on academic articles, recent consultancy reports, and case studies. More specifically, it examines and discusses the most representative social media applications in relation to the management of personal and collective knowledge, and it develops a framework for the articulation of personal-collective knowledge using social media.

\section{Literature Review}

\subsection{Managing Knowledge: a Collective Perspective}

Collective knowledge refers to knowledge that is common to all members of an organization and can be defined as "knowledge of the unspoken, of the invisible structure" (Baumard 1999). Collective knowledge is also often defined as knowledge of an environment of established rules,

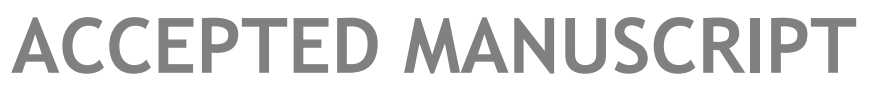




\section{ACCEPTED MANUSCRIPT}

laws, and regulations (Newell et al. 2009). Collective knowledge can be associated with "organizational knowledge" and/or with the organizational culture. From this organizational culture perspective, knowledge workers' minds on the basis of years of experience become a repository of "how things work here". Collective knowledge can be also defined as the result of individuals contributing their personal knowledge to "best practices-lessons learned, repositorybased" knowledge systems (King and Marks 2008). In many studies, the emphasis on collective knowledge is related to how organizations should motivate and support employees who may have useful knowledge to share it through KM systems (King and Marks 2008; van den Hooff, Schouten, and Simonovski 2012; Cabrera and Cabrera 2002; Wasko and Faraj 2005) or to factors that influence the management of knowledge in organizations (Holsapple and Joshi 2000; Kirchner, Razmerita, and Sudzina 2008).

Collective Knowledge Management (CKM) refers to a set of processes and tools that are used to manage knowledge at the level of a group or organization. Collective knowledge systems are human-computer systems in which machines enable the collection and harvesting of large amounts of human-generated knowledge (Gruber 2008; Kapetanios 2008). CKM has been the main focus for the field of knowledge management, and it is usually associated with traditional knowledge management (Alavi and Leidner 2001). CKM can be defined as a joint commitment to perform some collective action (Gilbert 2001).

From an organizational knowledge creation perspective, collective knowledge can be defined as "the process of making available and amplifying knowledge created by individuals as well as 


\section{ACCEPTED MANUSCRIPT}

crystalizing and connecting it to an organizational knowledge system" (Nonaka and Von Krogh 2009).

\subsection{Managing Knowledge: A Personal Perspective}

Knowledge can be defined by taking into consideration two different perspectives: epistemology of possession and epistemology of practice (Cook and Brown 1999). From the epistemology of possession view, knowledge is personal. It is a possession of the human mind and a cognitive capacity or a resource. It constitutes an intangible asset for individuals. Epistemology of practice links knowledge to what people do, and it is "enacted" through practice. In this latter perspective, knowledge is associated with "knowing" - which emphasizes the active process and social nature of knowledge. However, the knowledge as possession view is, in most of the literature, associated with the management of knowledge in organizations (Newell et al. 2009). Knowledge has a profound personal dimension as it is created and processed by individuals and may be exchanged among them. Nonaka and Takeuchi (1995) emphasize the personal dimension of knowledge by defining it as "a justified true belief". Knowledge consists of what we know, 'know-what'; of truths, beliefs, judgments, 'know-how', methodologies, and so on. Knowledge emerges through interpretation of raw information, through deeper engagement with an activity, social processes, and justification of beliefs (Von Krogh 2012). Knowledge entails a tacitexplicit dimension that may be individually embodied or socially embodied in practice and holds potential for both individual and social action (Nonaka and Von Krogh 2009). Furthermore, it is considered that tacit knowledge is unarticulated, tied to the senses, movement skills, experiences, intuitions, or implicit rules of thumb. 


\section{ACCEPTED MANUSCRIPT}

Polanyi (1997) argues that the most important type of knowledge, tacit knowledge, is personal and hard to articulate. Knowledge is also personal in the sense that people have different interpretations and different ways of reasoning. Personal knowledge can include knowledge gained from memories, reading books, notes, documents, photographs, intuitions, personal contacts and relationships, what one has learned from colleagues, and what a person knows about the world (Martin 2000).

Personal Knowledge Management (PKM) consists of a collection of processes that an individual needs to carry out in order to gather, classify, store, search, and retrieve knowledge in his/her daily activities. Furthermore, knowledge is dynamic as it is created and recreated through social interactions among individuals in organizations. PKM focuses on helping an individual to be more effective in personal, organizational, and social environments (Pauleen 2009). It deals with development of skills and attitudes that lead to more effective cognition, communication, collaboration, creativity, problem solving, lifelong learning, social networking, and leadership (Pauleen 2009). Several definitions of PKM are encountered in the literature, reflecting distinct approaches and various perspectives; a thorough review of the PKM concept and its evolution focusing on the use of social software can be found in Razmerita, Kirchner, and Sudzina (2009). A first generation of PKM tools (including emails, calendars, chats) helped personal productivity, but did not support social interaction, group work, or collaboration. Nowadays, the range of PKM tools may include social software that allows people to create, organize, and share their knowledge, but also to socialize, extend personal networks, create an online identity, and collaborate on organizing and creating new knowledge (Razmerita, Kirchner and Sudzina 2009). The development of PKM can be divided into two types: skills-activity-centered and technology-

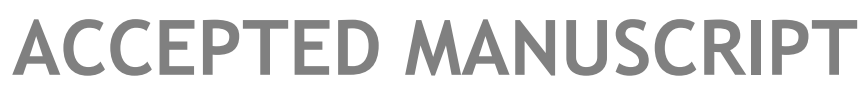




\section{ACCEPTED MANUSCRIPT}

centered (Cheong and Tsui 2010). While the first group focuses on skills of individuals to manage their knowledge, the second group concentrates on the classification, selection, and development of tools.

PKM is not a single system, but rather a set of applications (e.g., social networks, blogs) that can be used for managing knowledge, as well as professional and personal relationships. Yet, the "fragmentation of these systems and their lack of interoperability constitute important roadblocks towards the optimal usage for PKM” (Razmerita, Kirchner and Sudzina 2009). Privacy concerns are also potential barriers for the rapid adoption of these applications.

\subsection{The Articulation of Personal and Collective Knowledge}

Knowledge building can be understood as the interplay between individuals interacting in a collective place. The epistemology of practice, as introduced in the previous section, emphasizes the social and collective dimensions of knowledge. In organizations, knowledge creation is often a social process that is context-dependent. Personal knowledge and collective knowledge are distinctive but interrelated; furthermore, one of the main constituents of organizational knowledge is "interactions" (Bhatt 2002). When levels of interaction are kept to a minimum, most of the knowledge remains in control of the individuals. Interactive processes (such as informal get-togethers) enable individuals to enrich their knowledge and to make a part of their knowledge available to organizations. Knowledge that is internalized through organizations is created through interaction, and not by one member alone. According to Bhatt (2002), organizations may use the expertise of individuals in finding solutions to organization-related problems, but they cannot claim the right to individuals' knowledge.

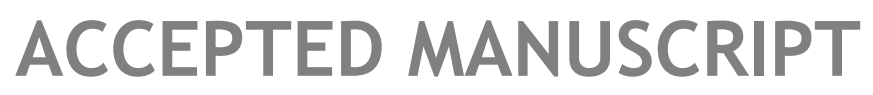




\section{ACCEPTED MANUSCRIPT}

Within knowledge-creating organizations, new knowledge, learning, and innovation are created through interaction between individuals, and making tacit knowledge explicit is the key to knowledge-creating organizations, as described by (Nonaka 2007). The SECI model defines knowledge creation as a spiraling process of interactions between explicit and tacit knowledge through four iterative processes: Socialization, Externalization, Combination and Internalization (SECI) (see Figure 1). Organizational knowledge creation stems from individual knowledge and, in particular, from tacit knowledge. Two dimensions of knowledge creation are proposed: the type of interaction (individual versus collective) and the media (face-to-face versus virtual). Knowledge is embedded in the "ba", defined as "a shared space for emerging relationships," that focuses on interaction (Nonaka and Konno 1998). Four types of ba are defined in the model. Originating ba is the place where individuals share their experiences or feelings in a face-to-face environment. In dialoging ba, individual mental models are shared and converted into common concepts. Systemizing ba deals with combining existing knowledge, while exercising ba offers a context for individualizing explicit knowledge.

The SECI model has been criticized for being too simplistic. The concept of the ba appears to be principally centered on a collective perspective and not an individual one, given that "the self is embraced by the collective when an individual enters the ba of teams" (Nonaka and Konno 1998). The transformation from individual to collective knowledge is considered as rather unproblematic despite the difference of interests, power, and collective dynamics that knowledge creation processes may encounter. A co-evolution model of individual and collective knowledge using wikis is provided by Kimmerle, Cress, and Held (2010). Learning and knowledge building are seen as an interplay between cognitive and social systems. People express their own

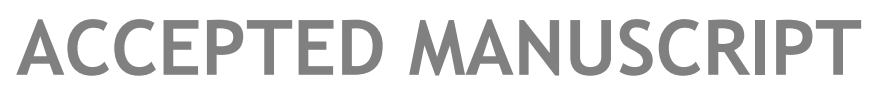




\section{ACCEPTED MANUSCRIPT}

knowledge using their cognitive system. To make it visible, they can share it in the form of shared digital artifacts (e.g., blog or wiki entries). New knowledge is created in an organization when people interact and share these digital artifacts - the content becomes manifest as collective knowledge. The question as to whether collective knowledge can develop depends on the extent to which users can change the existing content and on how conflicts can be handled if there are differences between new and existing ideas or practices. In the case of such conflicts, people can change their individual knowledge structures while connecting new content to existing content. In other words, the existing content has to be reorganized before new knowledge can be created.

PKM is not only the management of personal knowledge by individuals, but also the management of personal knowledge by the organization (Denyer, Parry, and Flowers 2011).

Organizational Knowledge Management (OKM) refers to the management of organizational knowledge by individuals and organizations. Both PKM and OKM are interconnected within a cyclical process including steps of "organizationalize," aggregate, personalize, and individualize. Nevertheless, it is everyone's personal decision to manage and share knowledge in an organization. 


\section{ACCEPTED MANUSCRIPT}

\section{Social media in organizations}

\subsection{The role of social media in organizations}

Organizations and researchers are in early stages of experimenting with social media in organizational contexts, hoping to reap the benefits of lightweight informal collaboration among employees (Brzozowski, Sandholm, and Hogg 2009; Skeels and Grudin 2009). Furthermore, some recent studies emphasize that social media can help knowledge conversion and team performance (Janhonen and Johanson 2011), and highlight that it can improve collaboration and communication within most companies (Andriole 2010; Huang, Baptista, and Galliers 2012). Other studies explore the dynamics of user belief in software application adoption (Lee, Yan, and Joshi 2010). Furthermore, social media facilitates new forms of elicitation and externalization of knowledge: self-initiated through blogs or wikis, or requested by others through forums or open questions (Razmerita, Kirchner, and Sudzina 2009).

On the basis of both academic articles and consultancy reports, this section investigates the role of social media in organizations and, in particular, focuses on how social media fosters articulation of personal and collective knowledge.

Enterprise 2.0 is the phenomenon that occurs when organizations adopt the tools and approaches of Web 2.0 (McAfee 2009). Enterprise 2.0 focuses on knowledge exchange through social interaction and collaboration among employees mediated by social media. This model tries to harness collective intelligence and accelerates the circulation of knowledge among people

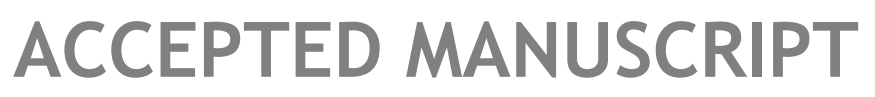




\section{ACCEPTED MANUSCRIPT}

(O'Reilly 2005). According to a McKinsey survey of 4,261 "global executives," the most popular social media tools used by companies are social networks, blogs, video sharing, and microblogging (Bughin, Byers, and Chui 2011). According to a report published by Deloitte, microblogs, blogs, and social networks support the identification of expertise, while wikis are important for preserving organizational memory (Miller, Marks, and DeCoulode 2011). The Altimeter group study of enterprise social networking consists of an analysis of social software, illustrating the difficulties related to the long-term adoption of these tools, and "the reality of everyday work [that] pushed enterprise social networks use to the side" (Li, Webber, and Cifuentes 2012). The concern of some organizations is that the technology would be used for non-business-related content that would impact productivity. Among the challenges of using social media listed in this study are poor experiences of employees, a lack of formalized strategy of social media usage in a company, or the inability to integrate social data (e.g., about customers and business partners) into already existing systems. The study concludes that, even for everyday social media practitioners, training of employees is still needed in order to deploy social media successfully.

Social media tools can be compared with respect to their ability to support enterprise processes, such as like the gathering of knowledge (most collected by Blogs, Wikis and Twitter), the generation of knowledge (connected to Twitter and Blogs), the dissemination of ideas and their development (connected to social network) (Voigt and Ernst 2010). The above-mentioned study also analyzes and compares alternative tools in relation to quality of the content generated (good for wikis and average for social network), the number of ideas generated (high in social network, less important in wikis), or the discussion around these ideas.

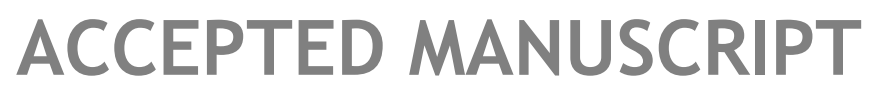




\section{ACCEPTED MANUSCRIPT}

An investigation of enterprise social networks and a framework of analysis for their adoption, potential risks, and the mechanisms for their management is advanced by Turban, Bolloju, and Liang (2011). Social software (on a scale high, medium or low) is evaluated with respect to its support of the knowledge processes and risks. Furthermore, the authors classify application of enterprise social networks into six categories: information dissemination and sharing, communication, collaboration and innovation, knowledge management, training and learning, management activities, and problem solving. Among the anticipated risks, five major types are identified: legal, security and privacy, intellectual property and copyright, user resistance, misuse, and abuse. The first three are related to user-generated content on social media, whereas the last two concern the use of social networks. Other challenges reported in the usage of social media in an organizational context include concerns regarding privacy, security, control, intellectual property, reputation, and proprietary information (Andriole 2010; Väyrynen, Hekkala, and Liias 2013). Furthermore, an analysis of tensions between knowledge management and social media can be addressed at three different levels: macro (organizational), meso (group), and individual (micro) using a set of key organizational factors (roles, ownership, control, and value) (Ford and Mason 2013).

On the basis of a case study, it has been found that the introduction of social media in a company is not enough, but that a dramatic change of the organizational culture toward an open and collaborative culture is necessary (Denyer, Parry, and Flowers 2011). Several case studies pinpoint the fact that employees have to devote time, and people need to be trained to use these tools correctly.

\section{ACCEPTED MANUSCRIPT}




\section{ACCEPTED MANUSCRIPT}

Social media technologies can be classified into six categories: social networks, blogs, wikis, podcasts, forums and content communities (Mayfield 2008). A more exhaustive range of social software, as discussed in (Kirchner, Razmerita, and Nabeth 2009), may include virtual worlds (e.g., SecondLife), content aggregators such as Real Simple Syndication (RSS) feeds, collaborative tagging (folksonomy) and social bookmarking sites (e.g., Delicious), and collaborative mapping or cognitive mapping tools (e.g., Mindmeister).

Here, we focus only on the most-used social software complemented with data from the literature review, surveys, and case studies in companies. Table 1 provides an overview of the main categories of social media that we analyze.

\subsection{Social Media for managing Personal and Collective Knowledge}

\subsubsection{Social Networking Sites (SNS)}

Social Networks Sites (SNS), such as Facebook, MySpace, or LinkedIn, represent an important facet of the "Internet social revolution." SNS can be defined as "web-based services that allow the individual to construct a public or semi-public profile within a bounded system, to articulate a list of other users with whom they share a connection and to view and traverse their list of connections and those made by others within the system" (Boyd and Ellison 2007).

Social networking services can be used in various ways: for management of professional relationships and professional networks (e.g., LinkedIn, Xing, Ryze), for personal social networks (e.g., Facebook, Friendster), and for communities of interest (Orkut, Tribe). Furthermore, professional Social Networking sites (e.g., LinkedIn) can be used to identify 


\section{ACCEPTED MANUSCRIPT}

business contacts, candidates, and clients on a particular topic, to advertise jobs, to advertise services, or to announce credentials or availability for a new role (Thew 2008).

One of the first social networks used in an organizational context was BeeHive, deployed by IBM in 2007, with the goal of motivating employees to express themselves, so that other employees could get a picture of their colleagues on both personal and professional levels $(\mathrm{Wu}$, DiMicco, and Millen 2010; DiMicco et al. 2008). All information about a person is accessible for every employee, even when they are not directly connected. The setting up of this network was clearly aimed at encouraging personal knowledge sharing and intended, in particular, as a facilitator to share tacit knowledge. As discussed in previously mentioned articles, the analysis of the actual usage revealed other individual goals, such as career advancement, gaining influence, promotion, and progress of projects.

Orange Plazza (Filippone 2011) is the global enterprise social networking site of the company France Telecom-Orange launched in December 2010. The goal of Plazza was both to create enriched personal profiles so that the employees could make available not only their profile information, but also more personal information, and to facilitate knowledge exchanges via communities of practices, help communities, or nonprofessional communities. Plazza is strictly voluntary (not subject to managerial approval), being based on free will and trust. Employees are free to create or join professional or personal communities. Nevertheless, in this case, important internal communication and animation were conducted, and a positive attitude towards the project was promoted by the managers. 


\section{ACCEPTED MANUSCRIPT}

While the traditional social networking sites appear to be mainly aimed at the individual (and peer-to-peer interaction), the actions in a social networking system (SNS) remain strongly socially oriented by the desire to communicate better with peers and to construct a social/professional identity and reputation. SNSs provide an excellent illustration of the articulation between personal and collective knowledge: people may use a SNS as a personal tool to manage their personal relationships and share their personal knowledge and experiences. At the same time, these SNSs may also be used by people to build and maintain their relationships (or social capital) or to communicate their activities (via streams), and thus contribute toward establishing trust and raising the level of awareness of current actions of the individuals and knowledge sharing.

\subsubsection{Wiki-on-line Collaboration and Crowdsourced Content}

Wiki applications facilitate collaborative editing of a web page supported by revision mechanisms that allow the monitoring of the edited section changes. Wikipedia is the most well-known applications of wikis, consisting in a global encyclopedia, authored by an open community of participants that has successfully harnessed collective knowledge. Wikipedia has grown tremendously in the last years and, currently, it is the sixth most accessed website in the world (according to Alexa traffic ranking). Wikis, and in particular Wikipedia, have been associated with the "free culture movement" - promoting the freedom to distribute and modify creative works and has been established as a principle of mass collaboration (Tapscott and Williams 2008). Wiki culture tends to suppress individualism in favor of a more collective vision in which the individual contributions disappear in the crowd.

\section{ACCEPTED MANUSCRIPT}




\section{ACCEPTED MANUSCRIPT}

Wikis provide a collaborative environment wherein authors contribute pieces of knowledge that are woven into a whole. Wiki technology can be used as a community platform, but also as a personal authoring environment. In a case study of a small IT consultancy company (Razmerita and Kirchner 2011), wikis were first implemented as a tool for collecting personal knowledge obtained in projects over time so that it could be reused in other projects. The wiki idea spread, and the wiki became an organizational knowledge management tool where all company members could contribute their experiences. This wiki is particularly useful for new employees who need to learn about the company's activities and projects. However, limitations are also observed, such as a small number of active contributors (fewer than 10\%), and even fewer senior contributors.

Another case for a big company was reported by Mansour, Abusalah, and Askenäs (2011). Their wiki system contains collaboratively created contributions regarding organizational experience, but also contributions written by a single author based on personal experience. The wiki initiative was launched to capture knowledge (experiences, best practices) in a flexible way (compared to a traditional document management system). Employees perceived the benefit of accessing other people's knowledge, but also of sharing problems with colleagues. Additionally, it was used to help people connect with each other and to discover who were the experts.

A wiki may appear as the perfect illustration of a tool supporting the collaborative process, doing little for the individual: participants collaborate on the creation of common content, and agree to give up any claim to ownership of their contribution. Altruism may appear as one of the main drivers of their participation. However, a study conducted in Wikipedia suggests that altruism is

\section{ACCEPTED MANUSCRIPT}




\section{ACCEPTED MANUSCRIPT}

not the principal reason, but rather it is the opportunity for people with relatively low social ability to express themselves (Amichai-Hamburger et al. 2008). Due to the quality of the content, use of wikis (and, more generally, crowdsourcing) does not take place without difficulties (Korfiatis, Poulos, and Bokos 2006).

A study which examined wiki usage in companies found several challenges with adoption and long-term sustainability (Grudin and Poole 2010). Mismatches between executive and managerial and individual contributors' attitudes and practices are discussed. People have different skills and experiences, and they have a certain way of organizing information that may not be useful for, or cannot be understood by, other contributors. Furthermore, it is difficult to organize knowledge and remove outdated information. Wikis are usually introduced in an already existing IT landscape, so it is not easy for employees to know when to use which tool, and whether they are allowed to correct other contributions. Moreover, wikis are not useful for managing all types of information.

\subsubsection{Blogs}

Blogs are online journals consisting of discrete entries typically displayed in reverse chronological order so the most recent post appears first. They can chronicle the lives and opinions of their authors. They can be devoted to politics or news, sharing opinions, or be concerned with technical developments. Most blogs are primarily textual, although some other forms of blog exist (e.g., photoblogs, videoblogs, and MP3 blogs for music collections). An important feature of blogs is the possibility for readers to leave comments, allowing the main author to engage in an interaction with his/her audience. Blogging provides the possibility for 


\section{ACCEPTED MANUSCRIPT}

people to develop an online identity that they are able to project into a larger "social" space (the blogosphere). Blogs also offer notification mechanisms, such as the availability of updates, as well as syndication services (RSS feeds). People blog for five reasons (Nardi, Schiano, and Gumbrecht 2004):

- Update others on activities and whereabouts

- $\quad$ Express opinions to influence others

- $\quad$ Seek opinions of others and gain their feedback

- $\quad$ 'Think by writing'

- Release emotional tension

There are three types of blogs: personal journal, "filters" (because they select and provide commentary on information from other websites), and "knowledge logs" (Herring et al. 2004). A majority of blogs $(70 \%)$ belong to the online diary type.

Employees use the enterprise blog either because it is their job responsibility, or of their own accord because they have something important to say (Kirchner, Razmerita, and Sudzina 2008). Experiences and company news are written down. The problem with blogs is that even though some knowledge becomes outdated over time, people do not delete it. In a case study done in a large technology corporation, Yardi, Golder, and Brzozowski (2009) found that new employees liked the possibilities of blogging, while employees who had worked in the company for a long time had rather low expectations. The attitudes toward blogging also depended on the attention

\section{ACCEPTED MANUSCRIPT}




\section{ACCEPTED MANUSCRIPT}

they received from others. Some challenges of blog usage are presented in a case of an ICT division of a large public financial organization (Baxter, Connolly, and Stansfield 2010). Employees were unsure of how to blog, what to blog, and how the blog should be used. The management did not encourage blog usage, and there was no blog moderation. Training sessions and blogging guidelines helped in successfully adopting blogging throughout the organization.

Blogging is a good illustration of services combining the personal and the collective perspectives. People use personal blogs to record personal information and opinions. At the same time, this information is made available to a worldwide community of bloggers (the whole blogosphere) and allows the individual to enter into interaction with others, with the possibility to control the communication space. Contrary to a discussion forum, a blog remains controlled by the individual, others being invited only to comment on the posting of the blog owner.

At the same time, global tools can be used to mine the blogosphere, allowing to tap into this global intelligence, for instance to identify trends (Klamma, Cao, and Spaniol 2007).

\subsubsection{Microblogs (Twittering)}

Microblogs allow users to exchange small elements of content, such as short sentences, individual images, or video (Kaplan and Haenlein 2010) using a maximum of 140 character messages in a social network to communicate about their daily activities, to advertise events, and/or to share information. Microblogging can play a key role in the quick diffusion of ideas within social network via viral marketing mechanisms (Huberman, Romero, and Wu 2008). The 


\section{ACCEPTED MANUSCRIPT}

connections in this social network are constituted by the users that have common interests and the users that follow this particular user (referred to as 'the followers' in Twitter).

Internal microblogs in Siemens started in 2009 and had about 500 authors among the 7,300 registered users from more than 70 countries (Müller and Stocker 2011). The content of the contributions was mostly business related; only rarely were personal issues discussed. From the personal perspective, the benefit of obtaining knowledge from experts and of staying informed was mentioned. From the organizational point of view, microblogging enables networking and knowledge sharing. As indicated in their study, the business value of microblogs is difficult to predict. Employees have the freedom to develop their own usage practice, so an effective adoption takes time. Some users might stop using the system at an early stage or not even start to use it because they consider it a waste of time, especially when the business value is not clear to them or it does not relate to their job responsibilities.

As reported in a study of a large company, a benefit of using the company's microblog is that employees can know what others are working on (Zhang et al. 2010). However, they find it difficult to identify conversation threads and have security concerns about sharing sensitive information.

Microblogging has had a very fast adoption rate over the last several years. Microblogging is very individualistic, decentralized (peer to peer), and strongly controlled by users, as each user can instantly decide to connect or disconnect with another user. Furthermore, it offers the possibility to block other users from following them. Just like other systems, such as blogs or 


\section{ACCEPTED MANUSCRIPT}

social networks, microblogs are used by some users to increase their visibility on the Internet, allowing them to relay opinion, or providing a tool for opinion leaders.

\subsubsection{Content Communities (Ccom)}

Virtual communities or content communities include a strong social dimension and also draw on user-generated content. Video communities (YouTube) or e-commerce systems (eBay) incorporating reputation and auctioning mechanisms contribute to implementation of the Web vision of a social space supporting collaboration and social interaction (Chiu, Hsu, and Wang 2006). Content communities, such as discussion forums (e.g., Yahoo Answers) or video and photo communities, enable users to share various types of resources, ideas, and opinions from the individual perspective, but also to share experiences and best practices and to discuss problems with others. Users are not required to have a personal profile or only basic information is given about themselves. Communities can be classified as communities of interest, communities of relationship, communities of transaction, and communities of fantasy, for exchanging knowledge, brainstorming, finding friends, or conducting commerce (Hagel and Armstrong 1997). Cisco, as well as Google, use content communities for sharing recruitment videos, keynote speeches, or press announcements. A challenge for companies using Ccom is sharing copyright-protected material (Kaplan and Haenlein 2010).

Angehrn, Luccini, and Maxwell (2009) have explored the use of video-based communities in the context of the enterprise as a means to support and boost innovation processes. In practical terms, this approach relies on the video-based social platform InnoTube that consists of four coupled environments: a video exchange channel, a network visualization and navigation tool, a

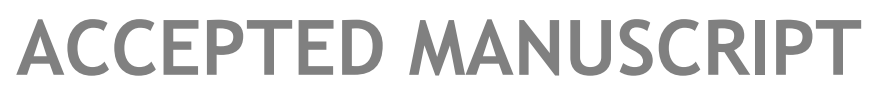




\section{ACCEPTED MANUSCRIPT}

profiles space, and a connection games space. The InnoTube platform has been tested in the car industry with the objective of trying out a new methodology for product development based on the proactive participation of representatives from different departments. Previously, new product development used to proceed in discrete stages without any collaboration between the different actors. In the new setting, the participants from the different departments were asked to watch videos and read attached material, to comment, discuss and rate the videos, to upload their own videos, and to present themselves (completing their profile) so as to connect with others. The participants confirmed their enthusiastic engagement and pointed out the usefulness of their experience in terms of gaining better knowledge of team members, accessing the know-how and ideas, and "enjoying" the process of finding or submitting relevant videos. In addition to organizational benefits from breaking the silos existing in the enterprise, this platform was also perceived by individuals as an enriching experience, allowing them to do their work in a more effective manner, while also bringing some personal satisfaction.

\section{Analysis}

In this section, we discuss how the management of personal and collective knowledge can be articulated using a two-step approach. First, we analyze benefits and limitations of the main categories of social software at both personal and collective levels. Second, we develop a framework of the articulation of personal and collective knowledge, and subsequently discuss it with the organizational knowledge creation theoretical model proposed by Nonaka et al. and introduced earlier in section 3.3. (Nonaka, Toyama, and Konno 2000; Nonaka, Von Krogh, and Voelpel 2006). 


\section{ACCEPTED MANUSCRIPT}

Social media include both a strong social and personal dimension: people use blogs as a way to express and record their thoughts and actions, and do so in a way that constitutes a digital memory that can be shared on the blogosphere. People use online social networking services (such as LinkedIn, Yammer, or Facebook) as a way to manage, interact, and keep track of their social relationships for personal and professional purposes. In all of these cases, the social software can be considered as an extensions of people's memory and have a clear role to play as personal knowledge management tools for helping individuals manage their personal knowledge, collaborate, and interact with others. At the same time, this personal knowledge is also made available to the group, thereby contributing to the management of knowledge at a more collective and organizational level. For instance, the accumulated set of people's profiles that originates from personal knowledge processes also represents the modern form of the enterprise directory that is used in the identification of experts in the organization, and constitutes a typical example of collective knowledge.

Using social media, collective knowledge is enhanced with a stronger social dimension through the use of comments, tagging, interactions, ratings, and other mechanisms that foster participation. Based on community participation, algorithms can compute the top-rated resources, the most accessed resources, tag clouds or folksonomies, or recommendations, all of which are useful mechanisms for navigating and retrieving relevant resources. However, the problem of structuring and finding the relevant knowledge is still an important issue for social media integrated in an organizational environment (Kirchner, Razmerita and Sudzina 2008; Razmerita 2011). 


\section{ACCEPTED MANUSCRIPT}

Table 2 provides a comparison of benefits and costs (limitations) for the individual and the collective/organization on the basis of the analyses of case studies and the literature.

As we have shown in Table 2, social media does not support the personal or collective dimension alone, but it may support both dimensions synergistically. Furthermore, based on our literature review, another dimension that characterizes social media seems to be the level of participation and interaction. The usage of social media has a more individualistic or a more collectivistic perspective, and thus it can be controlled more by the individual or by the collective.

In Table 3, social media is classified into four categories according to the level of interaction (high, low) and the level of control (individual versus collective).

Certain tools, such as blogs and content communities, have a low level of interaction with respect to knowledge creation. For example, blogs are usually personal blogs and the person who has created the blog is in control of the content. The interaction is reduced to the possibility of adding comments or referring to the blog; the author of the blog can authorize whether other participants can add content. Being a personal tool means that the level of disclosure is high. Similar to blogs are microblogs. However, microblog entries can be "retweeted" and thus distributed in different personal networks by the followers. Content communities are platforms where the collective creates value by uploading or sharing resources, rating or commenting on them, and/or providing answers to questions, and therefore contain a strong collective dimension. The users of such platforms can rate and comment, but usually their users engage in very limited interaction and normally do not have personal relationships. Contrary to blogs, wikis facilitate collaborative editing of content through a web page and are therefore classified as tools with a

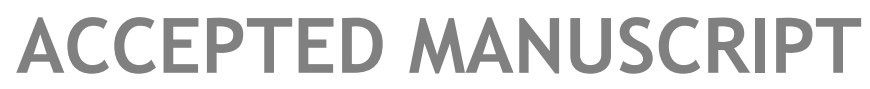




\section{ACCEPTED MANUSCRIPT}

higher level of interaction and with a stronger collective dimension and a low level of disclosure. As the content is created collaboratively, the collective is in control and individual contributions are not assigned to individual contributors, and this may be a reason why certain social software is underused. Social networking sites function on the basis of network effect and user-generated content, and are more interactive. The "network effect" is critical for the adoption of social media and for the synergetic articulation of personal-collective knowledge. The more people that use these SNSs, the more valuable the service becomes for organizations. The individuals control how much information they make available or share with their network of connections - the interactions are public and therefore the level of disclosure is high.

The level of interaction and participation is a critical indicator for the success of social media in organizations. Interactions are part of the interplay between tacit and explicit knowledge, between knowledge and "knowing", and can generate new knowledge and new ways of knowing (Cook and Brown 1999). Furthermore, various organizational factors, including the level of control, ownership, value, and roles, may generate certain tensions at individual, group, and organizational levels (Ford and Mason 2013) that may impact the adoption of social media for managing knowledge work.

This perspective that personal and collective knowledge are not totally separated but are part of a more holistic management of knowledge is also integrated in the model proposed by Nonaka, Toyama, and Konno (2000). This model defines two dimensions: the type of interaction and the type of media used in interactions. Media describes whether the interaction is face-to-face or through virtual media, such as like books, emails, or teleconferences. The interaction with others

\section{ACCEPTED MANUSCRIPT}




\section{ACCEPTED MANUSCRIPT}

in social media is always "virtual," but can be divided into low and high levels of interaction. Similar to the concept of ba, social media platforms provide a space for interaction and "emerging relationships."

\section{Conclusion}

Many systems dedicated to managing organizational knowledge have relied on the idea of extracting knowledge from people and making it available to the group, ignoring the very personal nature of knowledge and the individual needs of knowledge workers. Here, we argue that the management of knowledge may be constructed collaboratively using social media, and can potentially make the management of knowledge less cumbersome through the synergetic articulation of personal and collective knowledge.

The paper has introduced and explored a new perspective on leveraging social media in an organizational context and, in particular, has analyzed two distinct dimensions of knowledge: the personal and the collective perspective and their potential synergy through the adoption of social media. After introducing the Personal Knowledge (PK) and Collective Knowledge (CK) concepts along with social media, the paper surveyed different social software and classified it according to its role in managing knowledge-oriented processes at both the individual and collective levels.

The management of personal knowledge appears to be an integral part of collective knowledge management, as the personal and the collective dimensions can be connected in a symbiotic manner. Using the social media, personal and collective knowledge are not in opposition, but

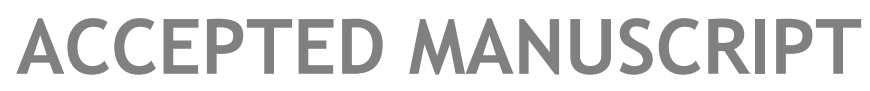




\section{ACCEPTED MANUSCRIPT}

represent different facets of complex knowledge processes. However, social media can be classified according to the level of control (as more individualistic or more collectivistic) and the level of interaction (low or high interaction) as presented in Table 3. With certain tools, individuals are more in control. These tools are used because they allow them to manage tasks and interactions more effectively - albeit with less interactivity. With other tools, the group is in control, resulting in a higher level of interaction and a diversity of knowledge and mindsets brought together. Such interactions are important for externalization of knowledge, learning and knowledge creation. Social media makes the management of knowledge possible as a way to augment collective intelligence by connecting and summing the individual intelligences in a harmonious manner. However, management needs to consider both costs and benefits at both individual and organizational levels (see Table 2). Furthermore, they need to create and foster an open organizational culture that encourages knowledge sharing, recognizes individuals, and encourages knowledge workers to adopt such tools.

\section{References}

Alavi, M., and Leidner, D. E. 2001. Review: Knowledge management and knowledge management systems: Conceptual foundations and research issues. MIS Quarterly 25(1):107136.

Amichai-Hamburger, Y., Lamdan, N., Madiel, R., and Hayat, T. 2008. Personality characteristics of Wikipedia members. CyberPsychology \& Behavior 11(6):679-681.

Andriole, S. J. 2010. Business impact of Web 2.0 technologies. Communications of the ACM 53(12):67-79. 


\section{ACCEPTED MANUSCRIPT}

Angehrn, A. A., Luccini, A. M., and Maxwell, K. 2009. InnoTube: a video-based connection tool supporting collaborative innovation. Interactive Learning Environments 17(3):205-220.

Arazy, O., Croitoru, A. 2010. The sustainability of corporate wikis: A time-series analysis of activity patterns. ACM Transactions on Management Information Systems 1(1):article 6.

Baumard, P. 1999. Tacit knowledge in organizations: Sage Publications London.

Baxter, G. J., Connolly, T. M., and Stansfield, M. H. 2010. Organisational blogs: Benefits and challenges of implementation. Learning Organization 17(6):515-528.

Bhatt, G. D. 2002. Management strategies for individual knowledge and organizational knowledge. Journal of Knowledge Management 6(1):31-39.

Boyd, D., M., and Ellison, N. B. 2007. Social network sites: Definition, history and scholarship. Journal of Computer-Mediated Communication 13(1):article 11.

Brzozowski, M. J., Sandholm, T., and Hogg, T. 2009. Effects of feedback and peer pressure on contributions to enterprise social media. Proceedings of the 2009 International Conference on Supporting Group Work.

Bughin, J., Hung Byers, A., and Chui, M. 2011. How social technologies are extending the organization. In McKinsey Quarterly, retrieved from http://www.mckinsey.com/insights/ high_tech_telecoms_internet/how_social_technologies_are_extending_the_organization

Cabrera, A., and Cabrera, E. F. 2002. Knowledge-sharing dilemmas. Organization Studies 23(5):687-710. 


\section{ACCEPTED MANUSCRIPT}

Cheong, R.K.F , and Tsui, E. 2010. The roles and values of personal knowledge management: an exploratory study. VINE: The Journal of Information and Knowledge Management Systems 40(2):204-227.

Chiu, C.-M. , Hsu, M.-H., and Wang, E.T.G. 2006. Understanding knowledge sharing in virtual communities: An integration of social capital and social cognitive theories. Decision Support Systems 42(3):1872-1888

Cook, S. D. N., and Brown, J. S. 1999. Bridging epistemologies: The generative dance between organizational knowledge and organizational knowing. Organization Science 10(4):381-400.

Denyer, D., Parry, E. and Flowers, P. 2011. "Social","Open” and "Participative”? Exploring personal experiences and organisational effects of Enterprise 2. 0 use. Long Range Planning $44: 375-396$.

DiMicco, J., Millen, D., Geyer, R. W., Dugan, C., Brownholtz, B., and Muller, M. 2008. Motivations for social networking at work. Proceedings of the 2008 ACM conference on Computer supported cooperative work:711-720.

Filippone, D. 2011. Un réseau social chez Orange pour replacer l'homme au coeur de l'entreprise Journal du Net, retrieved from http://www.journaldunet.com/solutions/intranet-extranet/ rseorange-plazza/.

Ford, D. P., and Mason, R. M. 2013. A multilevel perspective of tensions between knowledge management and social media. Journal of Organizational Computing and Electronic Commerce 23(1-2):7-33. 


\section{ACCEPTED MANUSCRIPT}

Gilbert, M. 2001. Collective preferences, obligations, and rational choice. Economics and Philosophy 17(1):109-119.

Gruber, T. 2008. Collective knowledge systems: Where the social web meets the semantic web. Web Semantics: Science, Services and Agents on the World Wide Web 6(1):4-13.

Grudin, J., and Poole, E. S. 2010. Wikis at work: success factors and challenges for sustainability of enterprise Wikis. Proceedings of the 6th International Symposium on Wikis and Open Collaboration, Article no. 5.

Haefliger, S., Monteiro, E., Foray, D., and von Krogh, G. 2011. Social software and strategy. Long Range Planning 44(5-6):297-316.

Hagel, J., and Armstrong, A. 1997. Net Gain: Expanding Markets through Virtual Communities. Harvard Business Press.

Herring, S. C., Scheidt, L. A., Bonus, S., and Wright, E. 2004. Bridging the gap: A genre analysis of weblogs. Proceedings of the 37th Annual Hawaii International Conference on System Science.

Holsapple, C. W., and Joshi, K. D. 2000. An investigation of factors that influence the management of knowledge in organizations. The Journal of Strategic Information Systems 9(23):235-261.

Huang, J., Baptista, J., and Galliers, R. D. 2012. Reconceptualizing rhetorical practices in organizations: The impact of social media on internal communications. Information \& Management 50(2-3):112-124. 


\section{ACCEPTED MANUSCRIPT}

Huberman, B., Romero, D., and Wu, F. 2008. Social networks that matter: Twitter under the microscope. First Monday 14(1).

Jackson, A., Yates, J., and Orlikowski, W. 2007. Corporate blogging: Building community through persistent digital talk. Proceedings of 40th IEEE Annual Hawaii International Conference on System Sciences:80.

Janhonen, M., and Johanson, J. E. 2011. Role of knowledge conversion and social networks in team performance. International Journal of Information Management 31(3):217-225.

Kapetanios, E. 2008. Quo Vadis computer science: From Turing to personal computer, personal content and collective intelligence. Data \& Knowledge Engineering 67(2):286-292.

Kaplan, A. M., and Haenlein, M. 2010. Users of the world, unite! The challenges and opportunities of Social Media. Business Horizons 53(1):59-68.

Kimmerle, J., Cress, U., and Held, C. 2010. The interplay between individual and collective knowledge: Technologies for organisational learning and knowledge building. Knowledge Management Research \& Practice 8:33-44.

King, W. R., and Marks P. V. 2008. Motivating knowledge sharing through a knowledge management system. Omega 36(1):131-146.

Kirchner, K., Razmerita, L. and Sudzina, F. 2008. New forms of interaction and knowledge sharing on Web 2.0. In: Web2.0: The Business Model, edited by E. Damiani, M. Lytras, P. Ordonez De Pablo, 21-37. USA: Springer Science and Business Media. 


\section{ACCEPTED MANUSCRIPT}

Kirchner, K., Razmerita, L., and Nabeth, T. 2009. Personal and collective knowledge management in the Web 2.0: Two faces of knowledge management. Proceedings of 9th International Conference on Innovative Internet Community Systems:15-26.

Klamma, R., Cao, Y., and Spaniol, M. 2007. Watching the blogosphere: Knowledge sharing in Web 2.0. Proceedings of International Conference on Weblogs and Social Media:105-112.

Korfiatis, N., Poulos, M., and Bokos, M.. 2006. Evaluating authoritative sources using social networks: an insight from Wikipedia. Online Information Review 30(3):252 - 262.

Lee, K., Yan, A., and Joshi, K.. 2010. Understanding the dynamics of users' belief in software application adoption. International Journal of Information Management 31(2):160-170.

Li, C., Webber, A. and Cifuentes, J.. 2012. Making the Business Case for Enterprise Social Networking: Focus on Relationships to Drive Value. edited by Altimeter.

Mansour, O., Abusalah, M., and Askenäs, L. 2011. Wiki-based community collaboration in organizations. Proceedings of the 5th International Conference on Communities and Technologies:79-87.

Martin, J. 2000. Knowledge management. The basis of corporate and institutional knowledge management. retrieved from www.spottedcowpress.ca/KnowledgeManagement/pdfs/ 06MartinJ.pdf

Mayfield, A. 2008. What is social media? retrieved from: http://www.icrossing.co.uk/ fileadmin/uploads/eBooks/What_is_Social_Media_iCrossing_ebook.pdf, Icrossing, March 2011. 


\section{ACCEPTED MANUSCRIPT}

McAfee, Andrew. 2006. Enterprise 2.0: The dawn of emergent collaboration. MIT Sloan Management Review 47(3):21-28.

McAfee, A. 2009. Enterprise 2.0: New Collaborative Tools for Your Organization's Toughest Challenges: Harvard Business School Press.

Miller, M., Marks, A., and DeCoulode, M. 2011. Social Software for Business Performance. The Missing Link in Social Software: Measurable Business Performance Improvements. edited by Deloitte.

Müller, J., and Stocker, A. 2011. Enterprise microblogging for advanced knowledge sharing. Journal of Universal Computer Science 17(4):532-547.

Nardi, B., Schiano, D. and Gumbrecht, M. 2004. Blogging as social activity, or, Would you let 900 million people read your diary? Proceedings of the Conference on Computer-Supported Cooperative Work:222-231.

Newell, S, Robertson, M., Scarbrough, H., and Swan, J. 2009. Managing Knowledge Work and Innovation: Palgrave Macmillan.

Nonaka, I. 2007. The knowledge-creating company. Harvard Business Review 85(7/8):162-171.

Nonaka, I., and Takeuchi, H. 1995. The Knowledge-Creating Company: How Japanese Companies Create the Dynamics of Innovation. New York: Oxford University Press.

Nonaka, I., and Konno, N. 1998. The concept of 'Ba': Building a foundation for knowledge creation. California Management Review 40(3):40-54. 


\section{ACCEPTED MANUSCRIPT}

Nonaka, I., Toyama, R., and Konno, N. 2000. SECI, Ba and leadership: A unified model of dynamic knowledge creation. Long Range Planning 33(1):5-34.

Nonaka, I., and von Krogh, G. 2009. Perspective-Tacit knowledge and knowledge conversion: Controversy and advancement in organizational knowledge creation theory. Organization Sciene 20(3):635-652.

Nonaka, I., von Krogh, G., and Voelpel, S. 2006. Organizational knowledge creation theory: Evolutionary paths and future advances. Organization Studies 27(8):1179-1208.

O'Reilly, T. 2005. What is Web 2.0? : retrieved from http://oreilly.com/web2/archive/what-isweb-20.html.

Pauleen, D. 2009. Personal knowledge management: Putting the "person" back into the knowledge equation. Online Information Review 33(2):221-224.

Polanyi, M. 1997. Personal Knowledge: Towards a Post-Critical Philosophy. Routledge

Razmerita, L. 2011. An ontology-based framework for modeling user behavior - A case study in knowledge management. IEEE Transactions on Systems, Man and Cybernetics - Part A: Systems and Humans 41(4):772-783.

Razmerita, L., and Kirchner, K. 2011. How wikis can be used to manage knowledge in SMEs: A case study. Business Information Review 28(3):175-178.

Razmerita, L., Kirchner, K. and Sudzina, F. 2009. Personal knowledge management: The role of Web 2.0 tools for managing knowledge at individual and organisational levels. Online Information Review 33(6):1021-1039. 


\section{ACCEPTED MANUSCRIPT}

Skeels, M. M., and Grudin, J. 2009. When social networks cross boundaries: A case study of workplace use of facebook and linkedin. Proceedings of the ACM 2009 International Conference on Supporting Group Work:95-104.

Tapscott, D., and Williams, A. D. 2008. Wikinomics: How mass collaboration changes everything: Penguin.

Thew, D. 2008. LinkedIn - A user's perspective. Business Information Review 25(2):87-90.

Turban, E., Narasimha, B., and Ting-Peng, L. 2011. Enterprise social networking opportunities, adoption, and risk mitigation. Journal of Organizational Computing and Electronic Commerce 21(3):202-220.

van den Hooff, B., Schouten, A. P., and Simonovski, S. 2012. What one feels and what one knows: the influence of emotions on attitudes and intentions towards knowledge sharing. Journal of Knowledge Management 16(1):148-158.

Voigt, K. I., and Ernst, M. 2010. Use of Web 2.0 applications in product development: An empirical study of the potential for knowledge creation and exchange in research and development. International Journal of Engineering, Science and Technology 2(9):54-68.

von Krogh, G. 2012. How does social software change knowledge management? Toward a strategic research agenda. The Journal of Strategic Information Systems 21(2):154-164.

Väyrynen, K., Hekkala, R., and Liias, T. 2013. Knowledge protection challenges of social media encountered by organizations. Journal of Organizational Computing and Electronic Commerce 23(1-2):34-55. 


\section{ACCEPTED MANUSCRIPT}

Wasko, M. M., and Faraj, S. 2005. Why should I share? Examining social capital and knowledge contribution in electronic networks of practice. MIS Quarterly 29(1):35-57.

Wu, A., DiMicco, J. M. and Millen, D.R. 2010. Detecting professional versus personal closeness using an enterprise social network site. Proceedings of the SIGCHI Conference on Human Factors in Computing Systems:1955-1964.

Yardi, S., Golder, S. A. and Brzozowski, M. J. 2009. Blogging at work and the corporate attention economy. Proceedings of the SIGCHI Conference on Human Factors in Computing Systems:2071-2080.

Zhang, J., Qu, Y., Cody, J. and Wu, Y. 2010. A case study of micro-blogging in the enterprise: use, value, and related issues. Proceedings of the SIGCHI Conference on Human Factors in Computing Systems:123-132. 


\section{ACCEPTED MANUSCRIPT}

Figure 1. SECI model and four types of ba adapted from (Nonaka, Toyama, and Konno 2000)

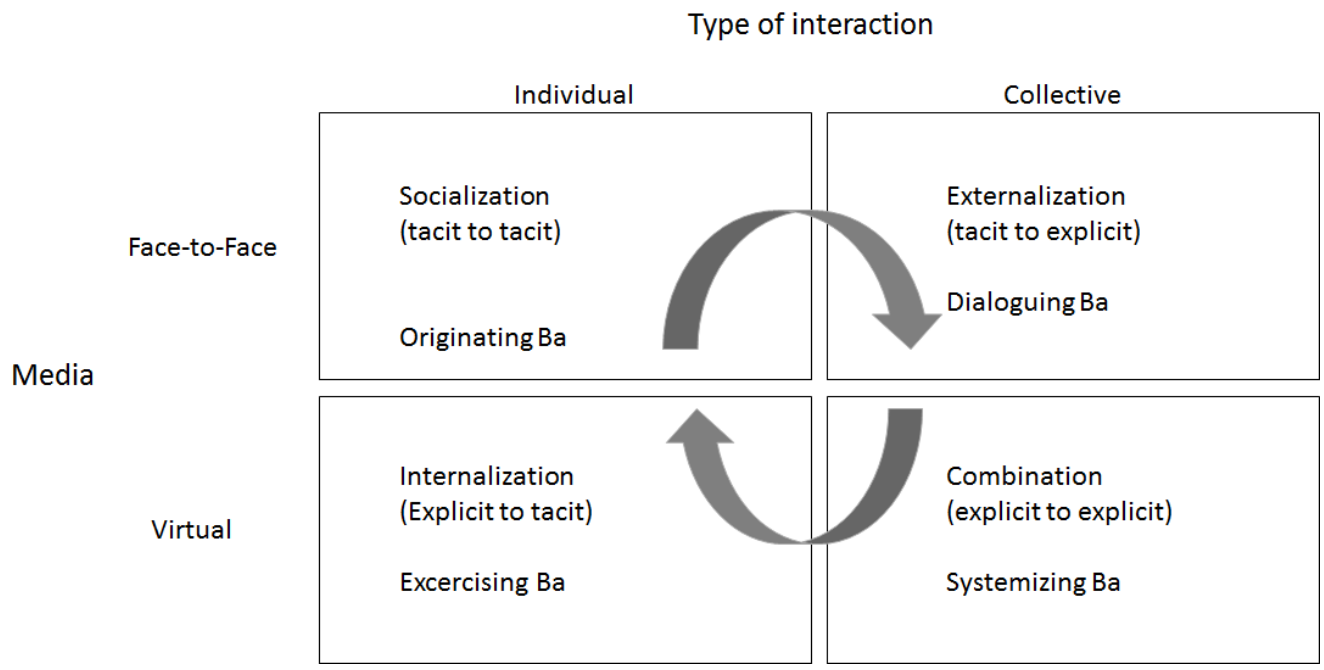




\section{ACCEPTED MANUSCRIPT}

Table 1. Overview of social media

\begin{tabular}{|c|c|c|}
\hline Social media & Function \& characteristics & Examples \\
\hline $\begin{array}{l}\text { SNS: } \\
\text { Social Networking } \\
\text { Sites }\end{array}$ & $\begin{array}{l}\text { "web-based services that allow the } \\
\text { individual to construct a public or } \\
\text { semi-public profile within a bounded } \\
\text { system, to articulate a list of other } \\
\text { users with whom they share a } \\
\text { connection and to view and traverse } \\
\text { their list of connections and those } \\
\text { made by others within the system" } \\
\text { (Boyd and Ellison 2007). }\end{array}$ & $\begin{array}{l}\text { LinkedIn, Facebook, Ning } \\
\text { Elgg, Yammer, Podio }\end{array}$ \\
\hline Wikis & $\begin{array}{l}\text { Wiki supports simple collaborative } \\
\text { editing of web page content enabling } \\
\text { simple, distributed and traceable } \\
\text { changes. }\end{array}$ & $\begin{array}{l}\text { MediaWiki, PBworks, } \\
\text { Brainkeeper, MoinMoin }\end{array}$ \\
\hline
\end{tabular}




\section{ACCEPTED MANUSCRIPT}

\begin{tabular}{|c|c|c|}
\hline $\begin{array}{l}\text { Blogs: } \\
\text { Weblogs }\end{array}$ & $\begin{array}{l}\text { Blogs are online journals consisting of } \\
\text { discrete entries typically displayed in } \\
\text { reverse chronological order so the } \\
\text { most recent post appears first; they are } \\
\text { used to chronicle the lives and } \\
\text { opinions of their authors. }\end{array}$ & $\begin{array}{l}\text { WordPress, } \\
\text { Blogger }\end{array}$ \\
\hline Mblogs: & $\begin{array}{l}\text { Microblogs enable users to send/read } \\
\text { maximum } 140 \text { character messages in a } \\
\text { message stream (social network) that } \\
\text { others can follow. It is used by people } \\
\text { to communicate, to advertise events, } \\
\text { to seek or share information. }\end{array}$ & $\begin{array}{l}\text { Twitter, } \\
\text { Communote }\end{array}$ \\
\hline $\begin{array}{l}\text { Content } \\
\text { communities }\end{array}$ & $\begin{array}{l}\text { Content communities contain } \\
\text { information in the form of text, voice, } \\
\text { image or video (e.g., via YouTube, } \\
\text { Flickr, Podcasts) everybody can share } \\
\text { information, rate or comment the }\end{array}$ & $\begin{array}{l}\text { YouTube, Tangler, Flickr, or } \\
\text { other platforms such as: } \\
\text { InnoTube }\end{array}$ \\
\hline
\end{tabular}




\title{
ACCEPTED MANUSCRIPT
}

\author{
content provided by the community.
}




\section{ACCEPTED MANUSCRIPT}

Table 2. Benefits and limitations of using social media for the individual and organizations

\begin{tabular}{|c|c|c|}
\hline Social media & $\begin{array}{l}\text { Benefits/Limitations for the } \\
\text { organization }\end{array}$ & $\begin{array}{l}\text { Benefits/ Limitations for the } \\
\text { individual }\end{array}$ \\
\hline $\begin{array}{l}\text { SNS } \\
\text { (DiMicco et al. } \\
\text { 2008; Wu, DiMicco } \\
\text { and Millen 2010; } \\
\text { Turban, Narashima } \\
\text { and Ting-Peng 2011; } \\
\text { Filippone 2011) }\end{array}$ & $\begin{array}{l}\text { foster personal } \\
\text { knowledge sharing } \\
\text { facilitate the exchange } \\
\text { of knowledge } \\
\text { support the creation of } \\
\text { enriched people directory } \\
\text { facilitate } \\
\text { communication } \\
\text { Limitations } \\
\text { time consuming } \\
\text { - }\end{array}$ & 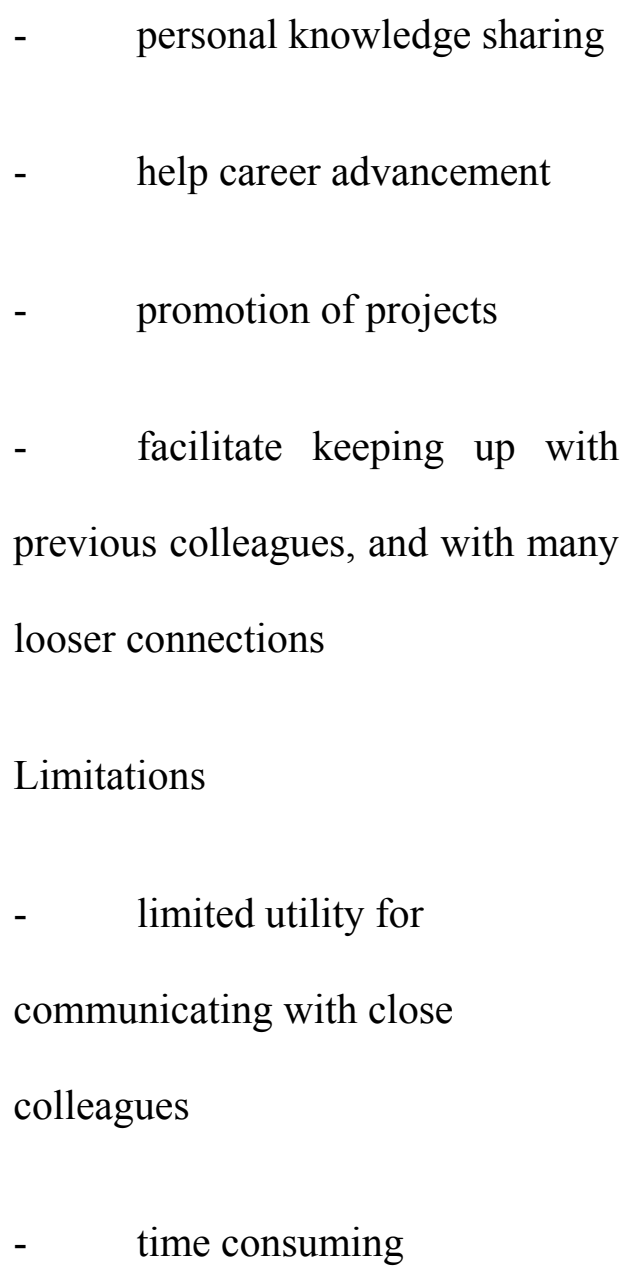 \\
\hline
\end{tabular}




\section{ACCEPTED MANUSCRIPT}

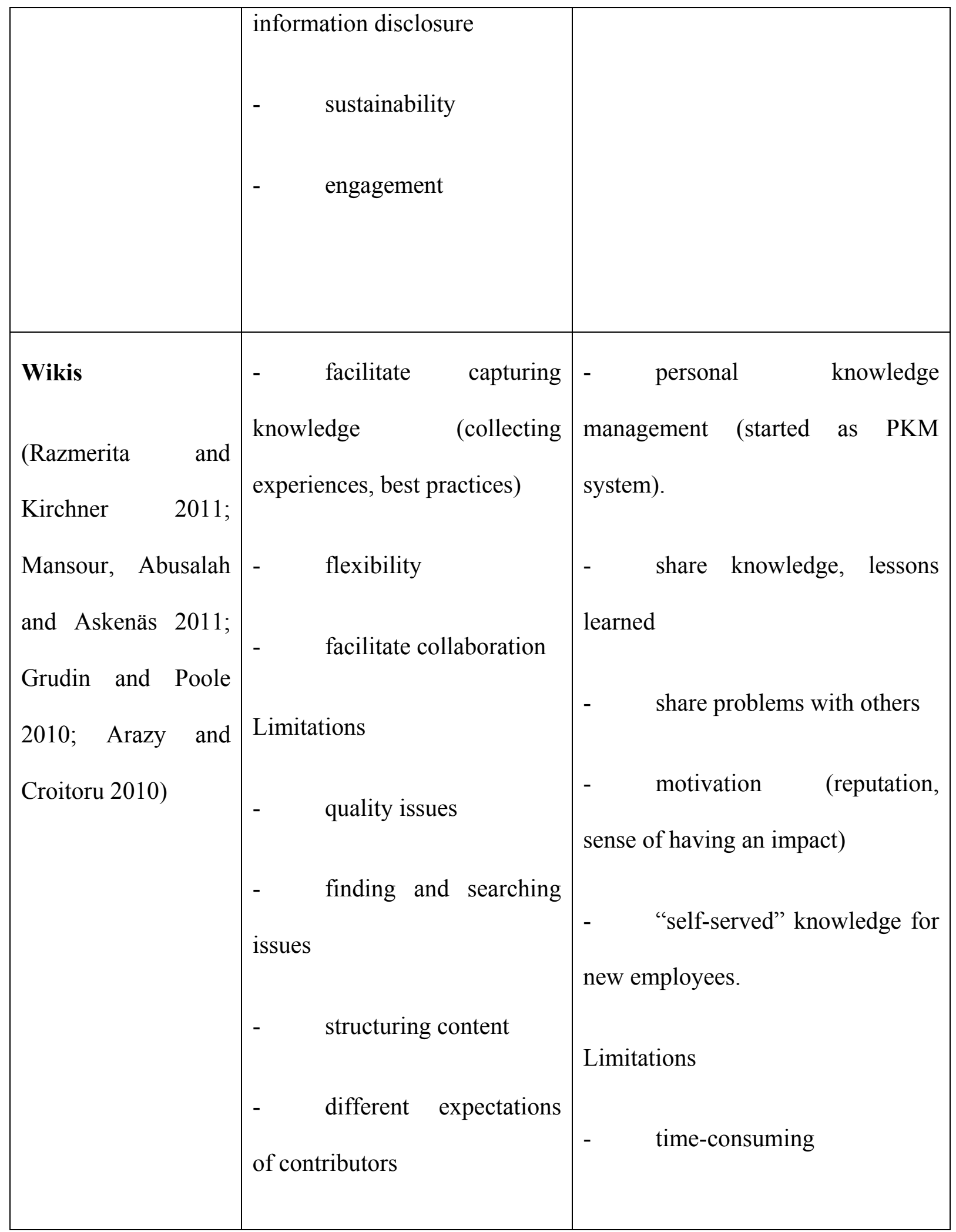




\section{ACCEPTED MANUSCRIPT}

\begin{tabular}{|c|c|c|}
\hline & $\begin{array}{l}\text { - few active contributors } \\
\text { and fewer senior contributors }\end{array}$ & $\begin{array}{l}\text { - } \text { IPR } \\
\text { - finding and searching } \\
\text { updated information }\end{array}$ \\
\hline $\begin{array}{l}\text { (Müller and Stocker } \\
\text { 2011; Zhang et al. } \\
\text { 2010) }\end{array}$ & 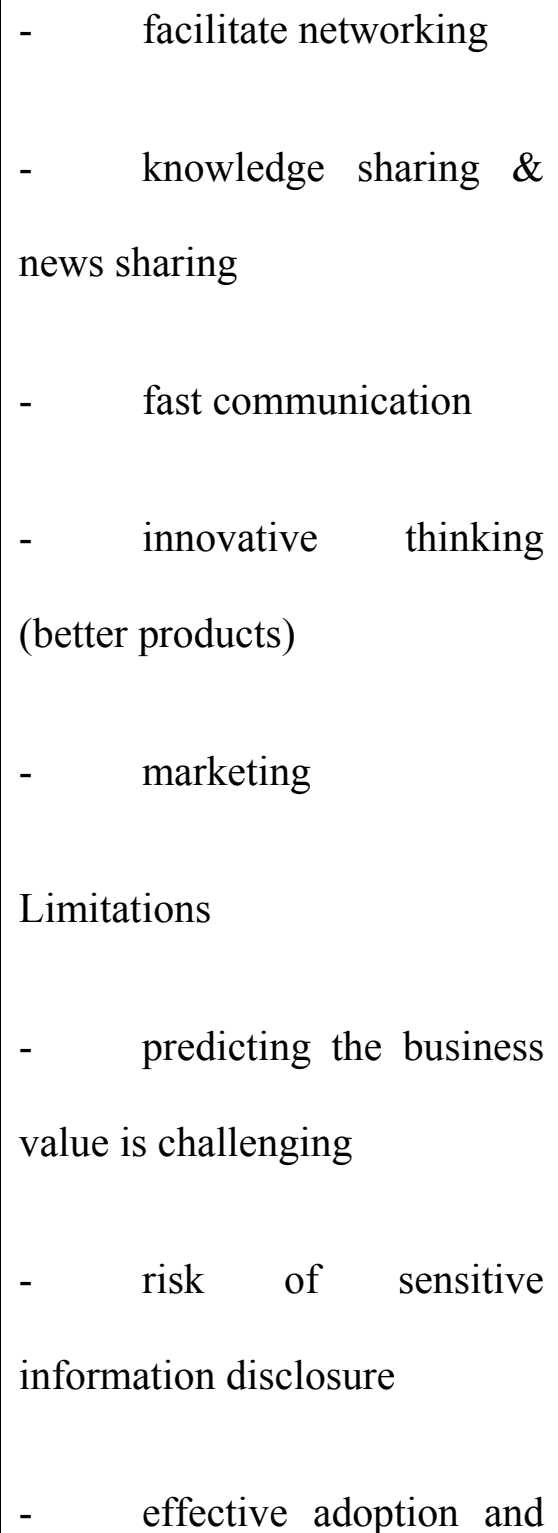 & 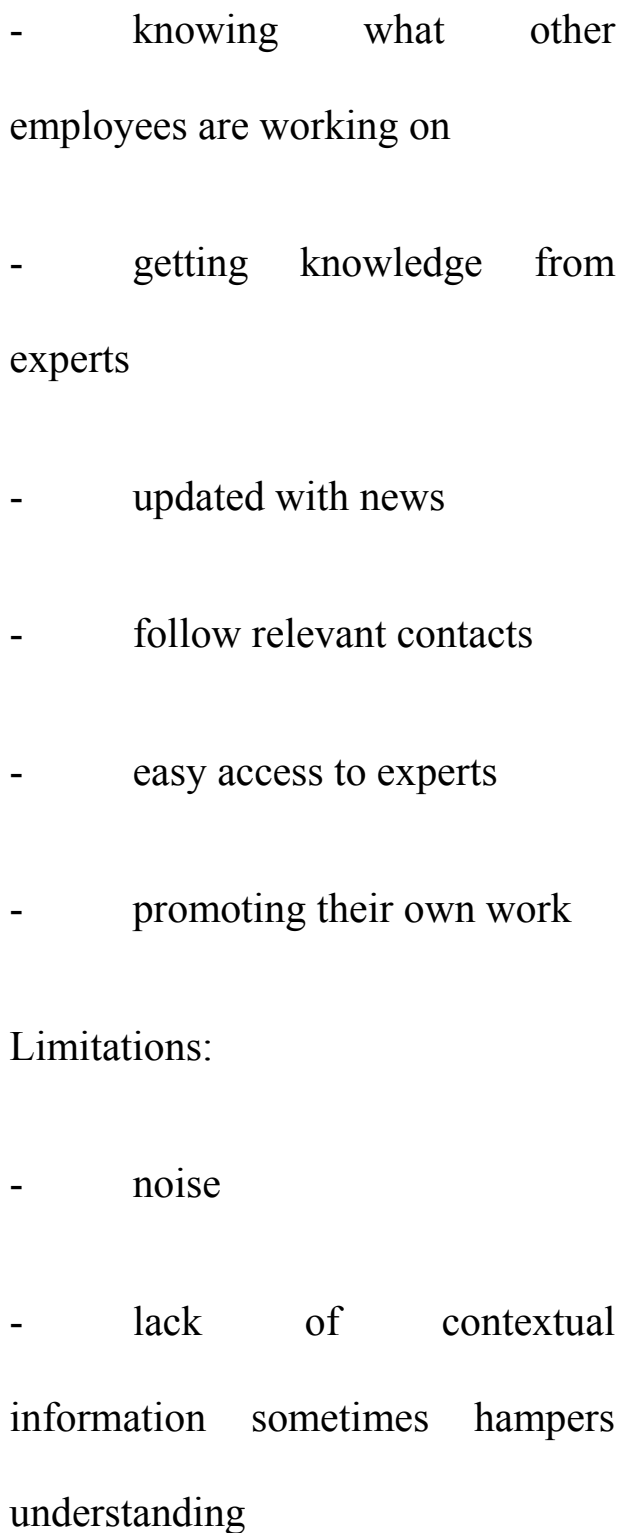 \\
\hline
\end{tabular}




\section{ACCEPTED MANUSCRIPT}

\begin{tabular}{|c|c|c|}
\hline & use takes time & search \\
\hline $\begin{array}{l}\text { Blog } \\
\text { (Kirchner, Razmerita } \\
\text { and Sudzina 2008; } \\
\text { Jackson, Yates and } \\
\text { Orlikowski 2007; } \\
\text { Baxter, Connolly } \\
\text { and Stansfield 2010) }\end{array}$ & $\begin{array}{l}\text { - internal communication } \\
\text { - easier expertise } \\
\text { location } \\
\text { improving } \\
\text { collaboration } \\
\text { Limitations } \\
\text { time-consuming } \\
\text { - } \\
\text { structuring and search } \\
\text { - } \\
\text { problems } \\
\text { training on what to blog } \\
\text { - }\end{array}$ & $\begin{array}{l}\text { - } \text { getting/sharing information } \\
\text { - } \text { engaging in dialogue } \\
\text { - gaining perspective and } \\
\text { "company pulse" } \\
\text { collaborating } \\
\text { support more informal } \\
\text { communication } \\
\text { Limitations: } \\
\text { time-consuming } \\
\text { blog unsure what and how to } \\
\text { - }\end{array}$ \\
\hline
\end{tabular}




\section{ACCEPTED MANUSCRIPT}

\begin{tabular}{|c|c|c|}
\hline $\begin{array}{l}\text { Content } \\
\text { Communities } \\
\text { (Angehrn, Luccini } \\
\text { and Maxwell 2009; } \\
\text { Kaplan and Haenlein } \\
\text { 2010) }\end{array}$ & $\begin{array}{l}\text { - collaboration and non- } \\
\text { linear innovation } \\
\text { more proactive } \\
\text { participation } \\
\text { Limitations } \\
\text { intellectual property } \\
\text { rights and copyright issues } \\
\text { technical difficulties } \\
\text { (firewall) }\end{array}$ & $\begin{array}{l}\text { - engagement and fun } \\
\text { - gaining better knowledge of } \\
\text { other team members } \\
\text { - accessing the know-how and } \\
\text { ideas }\end{array}$ \\
\hline
\end{tabular}




\section{ACCEPTED MANUSCRIPT}

Table 3. Level of interaction and control in social media

\begin{tabular}{|l|l|l|}
\hline \multirow{2}{*}{ Controlled by } & \multicolumn{2}{|c|}{ Level of interaction } \\
\hline Individuals & \multicolumn{1}{|c|}{ Low High } \\
\hline Collective & Blogs, Mblogs & SNS \\
\hline & Content communities & Wikis \\
\hline
\end{tabular}

